\title{
The relative importance of soil moisture in predicting bacterial wilt disease occurrence
}

\author{
Gaofei Jiang ${ }^{1}$, Ningqi Wang ${ }^{1}$, Yaoyu Zhang ${ }^{1}$, Zhen Wang ${ }^{1}$, Yuling Zhang ${ }^{1}$, Jiabao Yu ${ }^{1}$, Yong Zhang ${ }^{2}$, \\ Zhong Wei ${ }^{1}{ }^{,}$, Yangchun $\mathrm{Xu}^{1}$, Stefan Geisen ${ }^{3}$, Ville-Petri Friman ${ }^{4}$, Qirong Shen ${ }^{1}$
}

1 Key Laboratory of Plant immunity, Jiangsu Provincial Key Laboratory for Organic Solid Waste Utilization, Jiangsu Collaborative Innovation Center for Solid Organic Waste Resource Utilization, National Engineering Research Center for Organic-based Fertilizers, Nanjing Agricultural University, Nanjing 210095, China

2 College of Resources and Environment, Key Laboratory of Efficient Utilization of Soil and Fertilizer Resources, Southwest University, Chongqing 400715, China

3 Laboratory of Nematology, Wageningen University \& Research, Wageningen, The Netherlands

4 Department of Biology, University of York, YO10 5DD, UK

H I G H L I G H T S

- Soil moisture is a key predictor of bacterial wilt disease (BWD) across China.

- Other soil properties have lesser role and are locally associated to BWD.

- Soil moisture can causally drive BWD in greenhouse experiment.

- Water management strategies could potentially be used in BWD control.

\section{ARTICLE INFO}

Article history:

Received December 22, 2020

Revised February 9, 2021

Accepted February 24, 2021

Keywords:

Bacterial wilt disease

Soil moisture

Soil physicochemical properties

Rhizosphere bacterial communities

Ralstonia solanacearum

Random forest algorithm

\section{GRAPHICAL ABSTRACT}

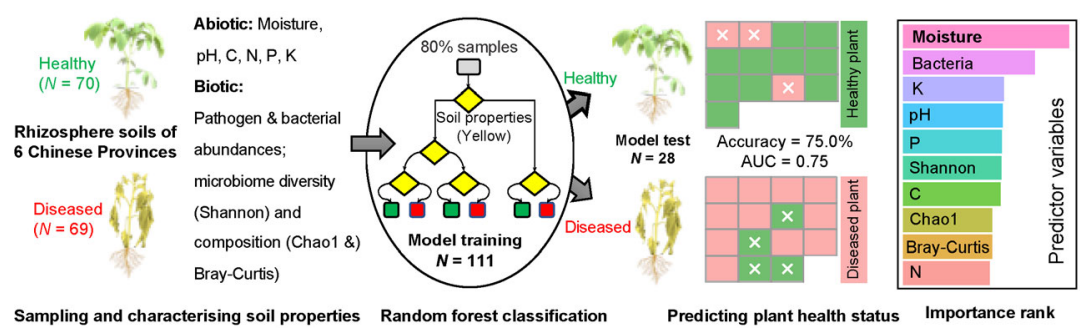

A B S TR A C T

Soil-borne plant diseases cause major economic losses globally. This is partly because their epidemiology is difficult to predict in agricultural fields, where multiple environmental factors could determine disease outcomes. Here we used a combination of field sampling and direct experimentation to identify key abiotic and biotic soil properties that can predict the occurrence of bacterial wilt caused by pathogenic Ralstonia solanacearum. By analyzing 139 tomato rhizosphere soils samples isolated from six provinces in China, we first show a clear link between soil properties, pathogen density and plant health. Specifically, disease outcomes were positively associated with soil moisture, bacterial abundance and bacterial community composition. Based on soil properties alone, random forest machine learning algorithm could predict disease outcomes correctly in $75 \%$ of cases with soil moisture being the most significant predictor. The importance of soil moisture was validated causally in a controlled greenhouse experiment, where the highest disease incidence was observed at $60 \%$ of maximum water holding capacity. Together, our results show that local soil properties can predict disease occurrence across a wider agricultural landscape, and that management of soil moisture could potentially offer a straightforward method for reducing crop losses to $R$. solanacearum.

() Higher Education Press 2021

\footnotetext{
* Corresponding author

E-mail address: weizhong@njau.edu.cn (Z. Wei)
} 


\section{Introduction}

Multiple physicochemical and biotic environmental factors have long been known to be important for plant disease outbreaks, as suggested by the conceptual Disease Triangle model (McNew, 1960). For example, soil moisture (Aung et al., 2018), pH (Rahman and Othman, 2020), nutrient availability (Berg and Koskella, 2018) and microbial communities (Trivedi et al., 2020) all influence the severity of soil-borne diseases. Furthermore, temperature can directly affect pathogen densities (Wei et al., 2015a; Pimentel and Ayres, 2018) or the strength of interactions between pathogen and its competitors (Wei et al., 2017; Velásquez et al., 2018) with important consequences for the disease occurrence. However, while the significance of environment has been long recognized (Cheng et al., 2019), we still poorly understand the relative importance of different factors, or their combinations, for the disease outcomes. Furthermore, the effects of soil properties are often studied locally within one specific agricultural area making it difficult to extrapolate results up to a level of a country or a continent (Janvier et al., 2007; Orr and Nelson, 2018). To study this, we used China-wide sampling of tomato plant rhizosphere to identify key abiotic and biotic soil properties associated with bacterial wilt disease occurrence, and experimentally tested if one of the most important factors, soil moisture, could causally drive bacterial wilt disease incidence in a greenhouse experiment.

Ralstonia solanacearum bacterium is a causative agent of notorious bacterial wilt disease that leads to a systemic wilting of plants (Hayward, 1991). It can infect multiple important crops belonging to the Solanaceae family (e.g., potato, tomato and tobacco) and has a global distribution (Mansfield et al., 2012). Previous studies have identified associations with multiple soil physicochemical factors and $R$. solanacearum infections both in the field and greenhouse experiments (Hayward, 1991; Jiang et al., 2017; Wei et al., 2018; Siregar et al., 2020). For example, R. solanacearum-infected plants have previously been associated with increased soil moisture (Jiang, 2016), acidic pH (Li et al., 2017a) and high nitrogen availability (Dalsing et al., 2015; Y. Gu et al., 2020). These environmental factors could affect bacterial wilt occurrence directly by favoring the growth of the pathogen, as $R$. solanacearum needs to reach certain threshold density in the soil to express key virulence factors that are triggered by quorum sensing signaling (Genin and Denny, 2012; Peyraud et al., 2016, 2018). Alternatively, soil properties could have indirect effects on the pathogen via plants or associated plant rhizosphere microbiome. Plants have evolved sophisticated defense mechanisms against pathogens, and recent evidence suggests that environmental factors can directly affect plant immunity and defense hormone pathways (Velásquez et al., 2018). Rhizosphere microbiome also plays a crucial role in forming the first line of defense against invading pathogens, often considerably shaping the disease severity (Kwak et al., 2018; Wei et al., 2019, 2020). In general, diverse microbial communities can limit pathogen growth due to intense competition for nutrients, space and other resources (Wei et al., 2015b; S. Gu et al., 2020), or because they are likely to contain highly antagonistic species that can directly inhibit the pathogen for example by secreting antimicrobial molecules (Raza et al., 2016). Crucially, soil properties often determine the composition and diversity of rhizosphere microbiome and could hence indirectly affect the likelihood of $R$. solanacearum infections.

Understanding the potential role of soil properties in $R$. solanacearum infections is especially important because bacterial wilt dynamics often show high temporal and spatial variability both between and within fields (Wei et al., 2017, 2018). Previous work has shown that between-field variability could be driven by local fluctuations in temperature and humidity (Wei et al., 2017), while within-field variation could be explained by spatial differences in soil physicochemical properties or the composition of microbial communities, which both have been associated with disease outcomes previously (Wei et al., 2018, 2019; Lee et al., 2021). However, it is unclear which soil properties are relatively more important than the others, and if the previously observed patterns hold across a wider geographical area with varying local environmental conditions. To study this, we focused on six geographically separated tomato fields in China (area of 1.3 million $\mathrm{km}^{2}$ ) to explore the role of within- and between-field variation in abiotic and biotic soil properties for bacterial wilt disease occurrence. We first collected and analyzed 139 rhizosphere soil samples originating from healthy and diseased plants at every field and identified significant associations between the disease outcome, pathogen densities and different soil properties. Second, machine learning algorithm was used to identify the relatively most important soil properties associated with the bacterial wilt disease, whose importance was directly tested in a greenhouse experiment. It was found that despite considerable betweenfield variation, healthy and diseased plants were consistently associated with certain soil properties, which could predict bacterial wilt disease occurrence with $75 \%$ accuracy. Soil moisture, bacterial community composition and bacterial abundances were the most important predictors of disease by a random forest model, and soil moisture content treatment at $60 \%$ of maximum water holding capacity led to the highest levels of disease incidence in a controlled greenhouse experiment. Together, our findings suggest that local variation in abiotic and biotic soil properties can reliably predict bacterial wilt disease outcomes across large agricultural area.

\section{Experimental procedures}

\subsection{Sampling sites and collection of plant soil samples}

Soil samples were collected from tomato fields at six locations in Changsha of Hunan province $\left(112^{\circ} 58^{\prime} \mathrm{E}, 28^{\circ} 11^{\prime} \mathrm{N}\right)$, Ningbo of Zhejiang province $\left(121^{\circ} 67^{\prime} \mathrm{E}, 29^{\circ} 91^{\prime} \mathrm{N}\right)$, Nanchang of 
Jiangxi province $\left(115^{\circ} 51^{\prime} \mathrm{E}, 28^{\circ} 41^{\prime} \mathrm{N}\right)$, Nanjing of Jiangsu province $\left(18^{\circ} 57^{\prime} \mathrm{E}, 32^{\circ} 03^{\prime} \mathrm{N}\right)$, Nanning of Guangxi province $\left(108^{\circ} 21^{\prime} \mathrm{E}, 22^{\circ} 49^{\prime} \mathrm{N}\right)$ and Wuhan of Hubei province (114.31'E $30.52^{\prime} \mathrm{N}$ ) during tomato bacterial wilt disease outbreaks in the summer 2015. The sampled fields in Central (Hubei and Hunan), Eastern (Jiangsu and Zhejiang) and Southern (Guangxi) China recurrently experience $R$. solanacearum outbreaks (Jiang et al., 2017) and had suffered from bacterial wilt disease epidemics between 3 to 15 years based on communication with the local farmers. Within each sampling site, common local tomato cultivars were used: Solanum lycopersicum cv. "Hengkang \#1" in Changsha, "CTX 201" in Nignbo, "Hezuo 906" in Nanachang, "Guihong \#1," "Jipin" in Nanjing and "Huafan \#13" in Wuhan. At each sampling site, around 12 symptomatic (diseased) and 12 asymptomatic (healthy) tomato plants were chosen and randomly sampled at the early fruiting stage resulting in a total of 139 rhizosphere samples. Excess root soil was discarded by gently shaking and the remaining soil attached on the root surfaces was collected and considered as the rhizosphere soil (Wei et al., 2011). Around $10 \mathrm{~g}$ of fresh rhizosphere soil per plant was sampled and divided into two sealed $5 \mathrm{~mL}$ Eppendorf tubes to retain natural soil properties. One tube was cryopreserved in 5 $\mathrm{mL}$ of $30 \%$ glycerol at $-80^{\circ} \mathrm{C}$ to analyze biotic properties of rhizosphere samples (pathogen and total bacteria densities and microbial community diversity and composition). Another tube was used for determining soil physicochemical (abiotic) properties as described in the following section.

\subsection{Determination of abiotic and biotic soil properties}

\subsubsection{Abiotic properties}

Abiotic physiochemical properties included soil moisture content (Moisture, \%), pH, available phosphorus $(\mathrm{P}$, $\mathrm{mg} \mathrm{kg}^{-1}$ ), available potassium $\left(\mathrm{K}, \mathrm{mg} \mathrm{kg}^{-1}\right)$, water-soluble carbon $\left(\mathrm{C}, \mathrm{mg} \mathrm{kg}^{-1}\right)$ and total nitrogen $\left(\mathrm{N}, \mathrm{mg} \mathrm{kg}^{-1}\right)$. The difference in fresh and air-dried soil sample weight was used as a proxy of soil moisture for each rhizosphere sample. Soil $\mathrm{pH}$ was measured in a $20 \%$ water (w/w) suspension (Li et al., 2017a) using a pH meter (PB-10, Sartorius, Germany). Available $\mathrm{P}$ and $\mathrm{K}$ were extracted with hydrochloric acid and ammonium fluoride and measured using molybdenum blue method (Pansu and Gautheyrou, 2006). The water-soluble carbon and total $\mathrm{N}$ were determined by following a previous protocol (Pansu and Gautheyrou, 2006) using a multi $\mathrm{C} / \mathrm{N}$ analyzer 3000 (Analytik Jena AG, Germany).

\subsubsection{Biotic properties}

The total DNA was exacted from $\sim 0.25 \mathrm{~g}$ of cryopreserved rhizosphere soil using PowerSoil DNA Isolation Kit (Mobio Laboratories, Carlsbad, CA, USA) following the manufacturer's protocol. DNA quality and concentration were checked using a NanoDrop 1000 spectrophotometer (Thermo Scientific, Waltham, MA, USA). Soil DNA was subjected to $16 \mathrm{~S}$ rRNA (rRNA) Illumina amplicon sequencing to determine the diversity and composition of bacterial communities at Shanghai Biozeron Biological Technology Co. Ltd. The V4 hypervariable region of the 16S rRNA gene was amplified with the primer pair 563F (5'-AYTGGGYDTAAAGVG-3') and 802R (5'TACNVGGGTATCTAATCC-3'). All sequences were processed with QIIME (Caporaso et al., 2010). The OTU similarity cut-off was assigned at $97 \%$ identity level using USEARCH (Edgar, 2010). OTUs were assigned to corresponding bacterial taxa using the Ribosomal Database Project (RDP) database with the online version of the RDP classifier (Cole et al., 2014). The microbial community diversity was determined as Shannon diversity index (Shannon) and Chao1 richness index (Shannon) using the vegan $R$ package (Dixon, 2003) after removing $R$. solanacearum OTUs (Wei et al., 2018). Microbial community composition was quantified as a dissimilarity index (Bray-Curtis) based on average Bray-Curtis distance of each sample from each other at the OTU level. The pathogen and total bacterial densities were examined with qPCR using $R$. solanacearum-specific primer Rsol_fliC (Schönfeld et al., 2003) and general bacterial primer pair Eub338/Eub518 (Fierer et al., 2005). SYBR Premix Ex Taq Kit (TaKaRa Biotech. Co, Japan) was used following the manufacturers' protocol, and each sample was measured in triplicate using a 7500 Fast Real-Time PCR System (Applied Biosystems, CA, USA).

2.3 Establishing causality between soil moisture and bacterial wilt incidence in tomato

A greenhouse experiment was conducted in Yixing of Jiangsu province to test whether soil moisture can predictably drive the development of bacterial wilt disease under controlled environmental conditions. Experimental soils that were free of $R$. solanacearum were collected from a riverside of Zhangzhu town in Yixing: no $R$. solanacearum growth was detected using semi-selective agar medium (Wei et al., 2018). Tomato seeds (S. lycopersicum cv. "Jipin") were surfacesterilized with $\mathrm{NaClO}(3 \% ; \mathrm{v}: \mathrm{v})$ and germinated on moist filter paper for 2 days before sowing in sterilized nursery substrate (Huaian Agricultural Technology Development Ltd). Tomato seedlings were transplanted into plastic pots with five $\mathrm{kg}$ of homogenized dry soils at four-leaf stage. The soil moisture content was manipulated using five treatments with $40 \%$, $50 \%, 60 \%, 70 \%$, and $80 \%$ of maximum water holding capacity, and 12 replicate pots were used per treatment. This moisture range covered dry $(40 \%)$ and flooded $(80 \%)$ soils. Plants were acclimated in greenhouse conditions for three weeks before pathogen inoculation and then grown in the same conditions until the end of the experiment (constant temperature of $30^{\circ} \mathrm{C} \pm 3^{\circ} \mathrm{C}$, relative air humidity of $80 \%$, and $14 \mathrm{~h}$ of light and $10 \mathrm{~h}$ of dark daily cycle). Water content was kept constant in each treatment by adding sterile water to each pot accordingly. After three weeks of acclimatization, $R$. solanacearum pathogen strain QL-Rs1115 (a strong virulent reference strain) was inoculated to all pots using soil drenching method with resulting in final concentration of 5.0 
$\times 10^{6} \mathrm{CFU} \mathrm{g}^{-1}$ soil (Wei et al., 2011). The disease development was monitored on a daily basis and quantified as a disease index on a scale ranging from 0 to 4 where one whole number change corresponds to $25 \%$ increase in wilted leaves per plant (Schandry, 2017).

\subsection{Data analyses}

2.4.1 Comparing differences in abiotic and biotic properties of healthy and diseased plant rhizosphere samples

All measured abiotic and biotic properties were normalized between the range $0-1$ using min-max normalization before statistical analyses (Patro and Sahu, 2015). Nonparametric Wilcoxon rank sum test (Wilcoxon test) was used to compare differences between healthy and diseased plant rhizosphere soil samples (Cuzick, 1985). The microbial community composition was ordinated by principal coordinates analysis (PCoA) using Bray-Curtis distance and differences between healthy and diseased plant rhizosphere soil samples were compared using the nonparametric permutational multivariate analysis of variance (PERMANOVA, $P<0.05$, 999 permutations) using Adonis function in $\mathrm{R}$ vegan package (Dixon, 2003). Principal component analysis (PCA), based on the Euclidean distance of the range normalized values for overall abiotic and biotic properties, was used to visualize differences between healthy and diseased plants (FactoMineR R package (Lê et al., 2008); statistical significance tested using nonparametric PERMANOVA $(P<0.05)$ with 999 permutations using Adonis function in $\mathrm{R}$ vegan package (Dixon, 2003)).

2.4.2 Identifying key abiotic and biotic predictors for pathogen abundance and plant health

To identify key abiotic and biotic predictors for pathogen abundance, we build up a model using multiple linear regression function in $\mathrm{R}$ stats package (R Core Team, 2020) to predict $R$. solanacearum densities based on all measured soil properties. The relative importance of different predictors was estimated based on their significance for the model performance (\% of $R^{2}$ ) using Anova ( $R$ Core Team, 2020) and relweights functions in $\mathrm{R}$ (Kabacoff, 2015). To understand the relationship between environmental variables and disease incidence, we used Random forest approach using randomForest package in $\mathrm{R}$ as follows (Breiman et al., 2018). We first randomly selected $80 \%$ of the entire 139 sample data set as a training set $(n=111)$ to generate a classification model for predicting plant health status (healthy vs. diseased) based on soil abiotic (moisture, $\mathrm{pH}, \mathrm{P}, \mathrm{K}, \mathrm{C}, \mathrm{N}$ ) and biotic properties including Chao1, Shannon and Bray-Curtis metrices of the bacterial community in tomato rhizosphere soils. 10-fold cross-validation was performed 10 times using the $\mathrm{rfcv}$ function to select appropriate number of predictor properties whose importance and cross-validation curves were visualized by using the R ggplot2 package (Wickham et al., 2020). Remaining $20 \%$ of samples $(n=28)$ were used as a test set to predict plant health based on the abiotic and biotic rhizosphere soil properties.

2.4.3 Analysis of disease dynamics in a greenhouse experiment

The effect of soil moisture on disease dynamics was analyzed based on temporal changes in disease index values using a logistic growth curve (Schandry, 2017). The disease dynamics curves were fitted individually for each plant using gcFitModel function in R grofit-package (Kahm et al., 2010). As described previously (Wei et al., 2015b), this fit could be divided into three variables describing different stages of disease development: 1) lag phase referred to as the delay time of disease symptom onset after inoculation of the pathogen (early infection stage); 2) disease rate referred to as the exponential increase of disease progression (exponential infection stage); 3 ) area under progression of the disease dynamics curve (AUDPC) referred to as the overall severity of wilt disease (late infection stage). Shapiro-Wilk and Bartlett's tests were used to test the normality and homogeneity of the fitted variables using the $R$ stats-package. If the data matrix followed a normal distribution with homogeneous variances, ANOVA and post hoc Tukey's HSD tests were used to compare differences between different soil moisture groups $(P<0.05)$ using R multcomp-package (Hothorn et al., 2008). Otherwise, non-parametric Kruskal-Wallis and post hoc Dunn's tests were used for statistical analyses using $R$ agricolae package (Mendiburu, 2020).

\section{Results}

3.1 Rhizosphere soil properties vary between healthy and diseased plants

We first compared the abiotic physiochemical and biotic rhizosphere soil properties (Table 1) of diseased and healthy tomato plants across six sampled provinces in China. Pathogen densities were on average 15.79 times higher in diseased compared to healthy plants $(P<0.0001$, Wilcoxon test, Figs. S1 and S2), and also the other rhizosphere soil properties differed between diseased and healthy plants (Fig. 1, Figs. S1 and S2). Specifically, diseased plants were characterized by 1.15 times higher soil moisture $(P=0.001)$, and 10.53 times higher total bacterial densities $(P=0.0002)$ compared to the healthy plants (Wilcoxon test; Fig. 1A and Figs. S1 and S2). While other physiochemical soil properties, or microbial community diversity, did not differ between the diseased and healthy plants ( $P>0.05$; Wilcoxon test; Fig. 1A, Figs. S1 and S2), PCoA analysis revealed that microbial community composition varied depending on the plant health status $\left(R^{2}=0.10, P=0.002\right)$ and between provinces $\left(R^{2}=\right.$ $0.56, P=0.001$, PERMANOVA; Fig. $1 \mathrm{~B}$ and Fig. S3). Moreover, differences in microbial community composition between the healthy and diseased plants were locationspecific: significant differences were found in CS, NB, NJ and 
NN $(P>0.05)$ but not in NC or WH provinces $(P<0.05$, PERMANOVA; Fig. S3). Moreover, when analyzed together using PCA, abiotic physicochemical and biotic soil properties differed between provinces $\left(R^{2}=0.62, P=0.001\right)$, and between healthy and diseased plants within each province $\left(R^{2}=0.09, P=0.001\right.$, PERMANOVA; Fig. 1C and Fig. S4).

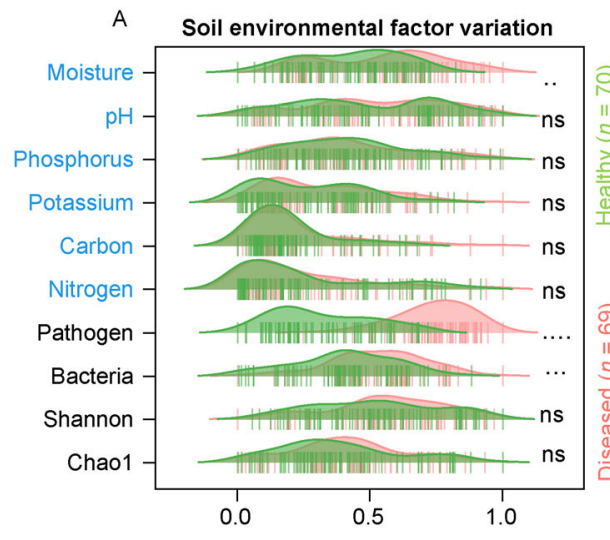

Normalised values of environmental factors
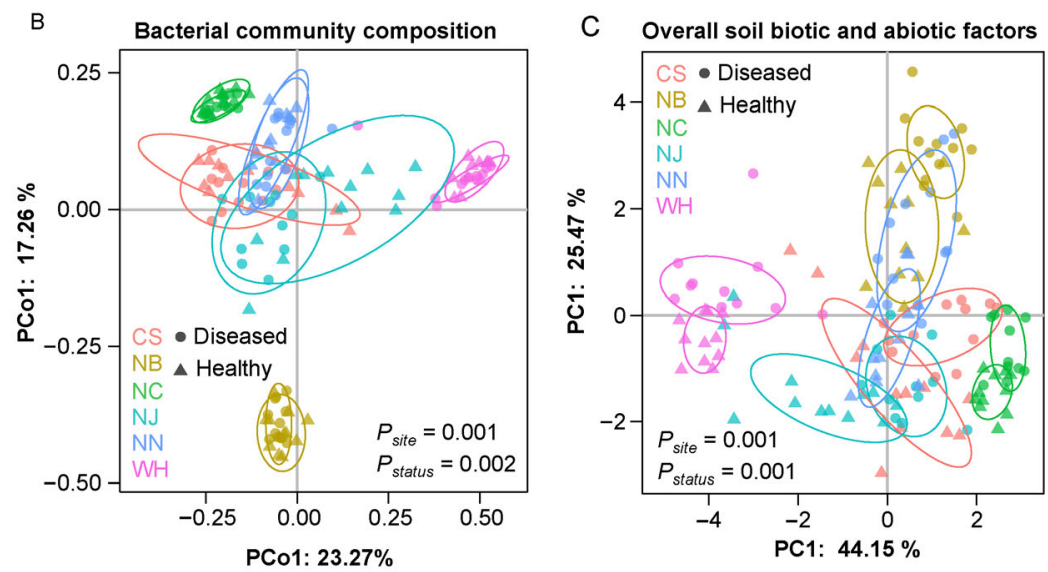

Fig. 1 Differences in abiotic physicochemical and biotic soil properties between healthy and diseased plants. (A) Comparison of the normalized physicochemical (blue) and biotic (black) parameters between healthy (green) and diseased (red) tomato plant rhizosphere samples (ns denote for non-significant correlation $(P>0.05)$ and stars $\left({ }^{* *},{ }^{* \star *},{ }^{* * * *}\right)$ denote significant correlation at levels $P<0.01, P<0.001$ and $P<0.0001$, respectively). Pathogen and total bacterial abundances are abbreviated as 'Pathogen' and 'Bacteria', respectively. $(\mathrm{B})$ Comparison of microbial community composition (PCoA) between healthy and diseased tomato plant rhizosphere samples (status) at each sampling location (site). (C) Comparison of abiotic soil physicochemical properties and biotic soil properties (PCA) between healthy and diseased tomato plant rhizosphere samples (status) at each sampling location (site).

Table 1 Differences in abiotic physicochemical and biotic soil properties between healthy and diseased plants

\begin{tabular}{|c|c|c|c|c|c|c|c|c|}
\hline \multirow[t]{2}{*}{ Factor } & \multirow[t]{2}{*}{ Name (units) } & \multirow[t]{2}{*}{ Statistical method } & \multicolumn{6}{|c|}{ Diseased vs healthy plants ( $P$-values) ${ }^{*}$} \\
\hline & & & CS & NB & NC & NJ & NN & $\mathrm{WH}$ \\
\hline Moisture & Soil moisture content (\%) & Wilcoxon test & $<0.001$ & 0.026 & 0.115 & 0.009 & 0.006 & 0.922 \\
\hline $\mathrm{pH}$ & Soil $\mathrm{pH}$ value & Wilcoxon test & 0.312 & 0.729 & 0.025 & 0.016 & 0.954 & 0.431 \\
\hline Phosphorus & Available phosphorus $\left(\mathrm{mg} \mathrm{kg}^{-1}\right)$ & Wilcoxon test & 0.514 & 0.63 & 0.606 & 0.079 & 0.862 & 0.224 \\
\hline Potassium & Available potassium $\left(\mathrm{mg} \mathrm{kg}^{-1}\right)$ & Wilcoxon test & 0.114 & 0.319 & 0.001 & 0.928 & 0.012 & 0.699 \\
\hline Carbon & Water-soluble carbon $\left(\mathrm{mg} \mathrm{kg}^{-1}\right)$ & Wilcoxon test & 0.799 & 0.378 & 0.599 & 0.009 & 0.008 & 0.047 \\
\hline Nitrogen & Water-soluble nitrogen $\left(\mathrm{mg} \mathrm{kg}^{-1}\right)$ & Wilcoxon test & 0.887 & 0.143 & 0.028 & 0.211 & 0.419 & 0.401 \\
\hline $\begin{array}{l}\text { Pathogen } \\
\text { density }\end{array}$ & $\begin{array}{l}R \text {. solanacearum density }\left(\log _{10} f l i C\right. \\
\left.\text { gene copies } \mathrm{g}^{-1} \text { soil }\right)\end{array}$ & Wilcoxon test & $<0.001$ & $<0.001$ & $<0.001$ & $<0.001$ & $<0.001$ & $<0.001$ \\
\hline $\begin{array}{l}\text { Bacterial } \\
\text { density }\end{array}$ & $\begin{array}{l}\text { Total bacterial density }\left(\log _{10} 16 S\right. \\
r R N A \text { gene copies } \mathrm{g}^{-1} \text { soil) }\end{array}$ & Wilcoxon test & 0.002 & 0.04 & 0.645 & 0.005 & 0.014 & 0.081 \\
\hline Shannon & $\begin{array}{l}\text { Shannon index for bacterial } \\
\text { community diversity (OUT level) }\end{array}$ & Wilcoxon test & $>0.999$ & 0.198 & 0.519 & 0.002 & 0.291 & 0.133 \\
\hline Chao1 & $\begin{array}{l}\text { Chao1 index for bacterial } \\
\text { community richness (OTU level) }\end{array}$ & Wilcoxon test & 0.755 & 0.977 & 0.133 & 0.002 & 0.198 & 0.401 \\
\hline Bray-Curtis & $\begin{array}{l}\text { Bray-Curtis dissimilarity index for } \\
\text { bacterial community composition }\end{array}$ & PERMANOVA test & 0.034 & 0.023 & 0.298 & 0.001 & 0.003 & 0.067 \\
\hline
\end{tabular}

*Sampling locations are abbreviated as follows: CS = Changsha, NB = Ningbo, NC = Nanchang, NJ = Nanjing, NN = Nanning

and $\mathrm{WH}=$ Wuhan. $P$-values less than 0.05 are shown in red color. Details of the analysis are listed in Supplementary Figs. $2-4$. 
Together, these results suggest that diseased and healthy plants were associated with distinct soil properties despite clear between-province variation in environmental conditions.

3.2 Soil moisture is the relatively most important factor distinguishing diseased and healthy plant samples

To compare the relative importance of different soil properties, we used correlation analysis and machine learning. We found statistically significant relationships between abiotic physicochemical and biotic parameters and $R$. solanacearum pathogen densities in case of all variables except for $P$ and $K$ availability $(P>0.05$, Fig. $2 \mathrm{~A}$ and Fig. S5). Specifically, pathogen densities correlated negatively with $\mathrm{N}$ availability $\left(R^{2}=0.24, P=0.005\right)$ and average Bray-Curtis dissimilarity (average Bray-Curtis distance of microbial community composition from other 139 samples, $R^{2}=0.28, P=0.001$ ). In contrast, pathogen densities were positively associated with total bacterial densities $\left(R^{2}=0.60, P<0.0001\right)$, soil moisture $\left(R^{2}=0.55, P<0.0001\right), \mathrm{pH}\left(R^{2}=0.28, P=0.001\right)$, Shannon diversity $\left(R^{2}=0.20, P=0.017\right)$ and Chao1 richness $\left(R^{2}=\right.$ $0.21, P=0.014$; Fig. 2 A and Fig. S5). Of all predictor variables, soil moisture (relative weight $=40.36 \%$ ), total bacterial density (relative weight $=22.77 \%$ ) and soil $\mathrm{pH}$ (relative weight $=$ $14.59 \%$ ) were the most significant predictors of pathogen densities in the tomato rhizosphere (multiple regression model, AIC: $324.09 ; F_{10,128}=10.6, R^{2}=0.45, P<0.0001$, Table S1).

Random forest modeling was further used to analyze associations between soil properties and plant health. By using all measured soil properties, we could predict bacterial wilt disease outcomes with $78.6 \%$ accuracy (AUC $=0.89$; Fig. S6). To eliminate the obvious link between pathogen abundance and disease incidence, we re-ran the model without pathogen density data (Fig. 2B). The high predictability of the model was retained, and bacterial wilt disease outcomes could still be predicted with $75 \%$ accuracy (AUC = 0.75; Fig. $2 \mathrm{C}$ ). Based on 10-fold cross-validation with 10 independent model simulations (inset of Fig. 2B), soil moisture was ranked as the most important individual predictor of plant health followed by the total bacterial abundances (Fig. 2B). Together, these results suggest that abiotic and biotic soil properties can reliably predict bacterial wilt disease occurrence, with soil moisture being the relatively most important factor.

3.3 Variation in soil moisture can causally drive bacterial wilt disease occurrence

To directly test if soil moisture can drive variation in bacterial wilt disease incidence, we performed a greenhouse experiment where tomato plants were exposed to $R$. solanacearum type strain under different soil moisture treatments. We found that bacterial wilt disease dynamics differed depending on soil moisture content and the stage of infection (Fig. 3). On average, the highest disease incidence was observed in $60 \%$ followed by $70 \%$ soil moisture content treatments, while no differences were observed between the other treatments (Fig. 3A-3B). Specifically, soil moisture effects were visible during the early stages of infection in terms of reduced lagphase of disease onset $\left(F_{4,21}=7.48, P<0.0001\right.$, ANOVA;

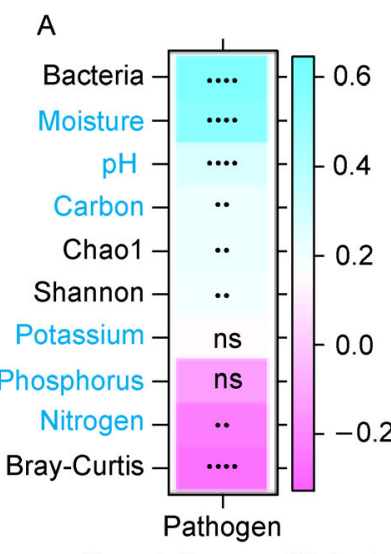

Correlation coefficient
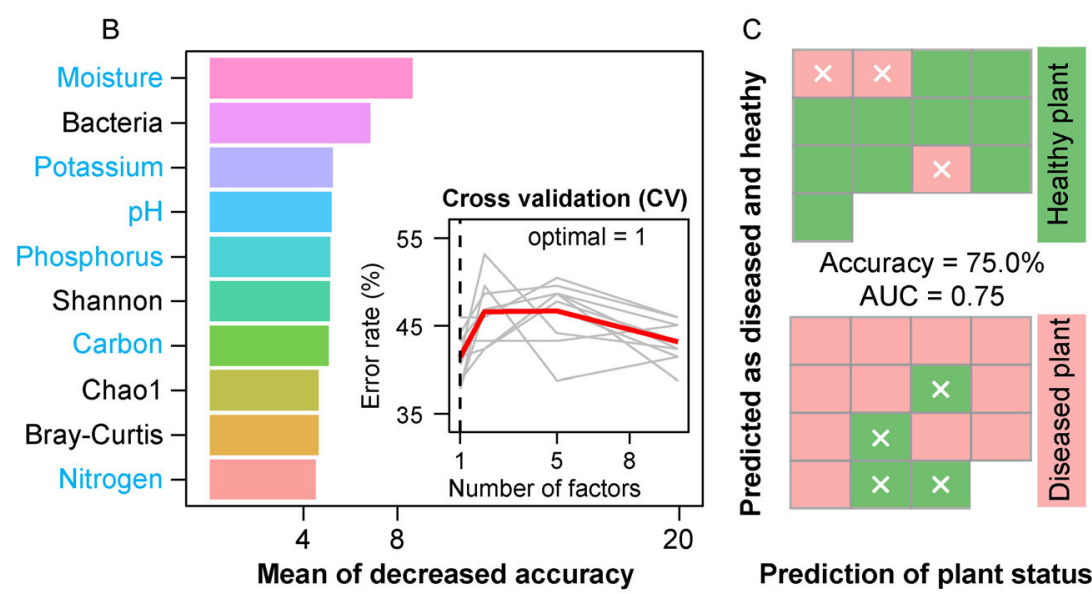

Fig. 2 The relative importance of abiotic physicochemical and biotic soil properties in predicting bacterial wilt disease occurrence. (A) Correlation coefficients (ranging from negative (purple) to positive (cyan)) between $R$. solanacearum pathogen densities and abiotic physicochemical (blue) and biotic (black) soil properties across all tomato rhizosphere samples (ns denote for non-significant correlation $(P>0.05)$ and stars $\left({ }^{* *},{ }^{* * *},{ }^{* * *}\right)$ denote significant correlation at levels $P<0.01, P<0.001$ and $P<0.0001$, respectively). (B) Relative importance rank of abiotic physicochemical (blue) and biotic (black) soil properties and $10-$ fold cross-validation of random forest model (inset in $\mathrm{B}$ ) based on the training set $(80 \%$ of randomly selected rhizosphere samples). Total bacterial abundances are abbreviated as 'Bacteria'. (C) Validation of random-forest model with a test set (20\% of remaining samples) predicting plant disease outcomes based on soil properties: green and red filled cells denote for correct predictions and filled cells with white crosses denote for false predictions. 

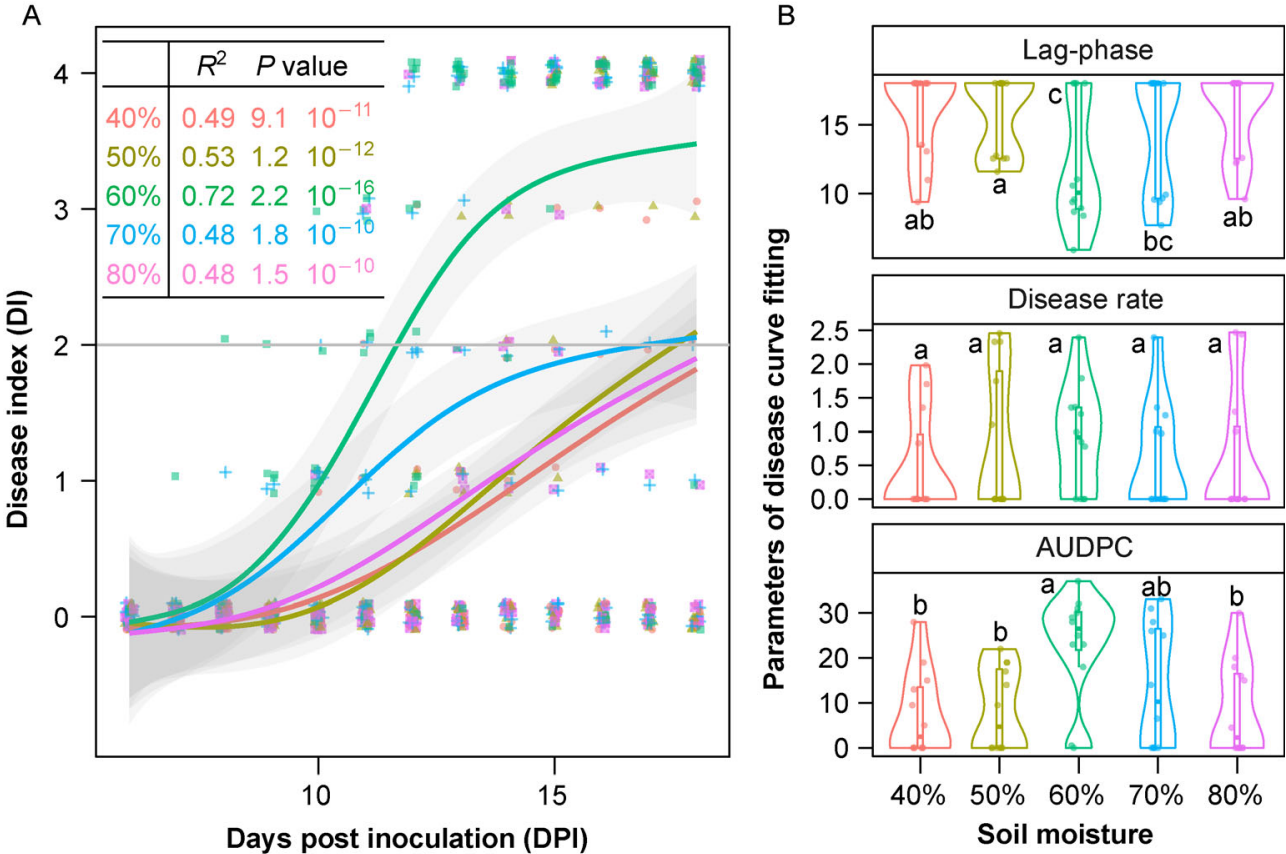

Fig. 3 Causal validation of the role of soil moisture driving bacterial wilt disease dynamics in a greenhouse experiment. (A) Mean disease progression curves in different soil moisture treatments based on logistic curve fitting (left inset shows goodnessof-fit and significance for each treatment). (B) Comparison of disease dynamics between different treatments in terms of lagphase before disease onset (early stage), disease rate (exponential stage) and area under progression of disease curve (AUDPC, late stage). Different small letters above violin plots denote for significant differences between treatment groups $(P<0.05)$.

Fig. 3B) and as overall differences in area under disease progression curve (AUDPC, $\chi^{2}=13.73, P=0.008$, AUDPC panel), while soil moisture content had no effect on the disease rate during the exponential phase of infection $\left(\chi^{2}=\right.$ 4.07, $P=0.396$, Kruskal-Wallis test; Fig. 3B). Together, these results demonstrate that soil moisture alone can causally drive bacterial wilt disease outcomes in otherwise homogenous tomato rhizosphere environments.

\section{Discussion}

Here we studied if plant-level variation in bacterial wilt disease occurrence could be explained by local abiotic and biotic soil properties across six provinces in China. Our sampling data shows that healthy and diseased plant rhizosphere soils were associated with distinct abiotic and biotic properties which could predict bacterial wilt disease occurrence with $75 \%$ accuracy. Soil moisture was identified as the most important predictor, and its causal role was tested directly in a greenhouse experiment with tomato. It was found that variation in soil moisture alone, could considerably change the disease dynamics resulting in different levels of disease incidence. Our results are in line with previous studies that have identified a tight link between moisture and plant diseases (Huber and Gillespie, 1992) with Pseudomonas syringae (Xin et al., 2016) and M. oryzae pathogens in plant phyllosphere (Li et al., 2014) and expands this association to crops and other soil-borne bacterial diseases.

Moisture could affect plant pathogens in several ways (Aung et al., 2018) ranging from effects on pathogen survival, movement and growth in the soil (Smilanick and Mansour, 2007; Kearns, 2010) to effects on pathogen invasiveness ( $\mathrm{Li}$ et al., 2014) or indirect effects on the activation of plant defenses (Panchal et al., 2016; Velásquez et al., 2018). While the relationship with moisture has previously been observed with other soil-borne pathogenic fungi and bacteria, including R. solanacearum (Chairman et al., 1981; van Elsas et al., 2000; Islam and Toyama, 2004; Satou et al., 2006; Mondal et al., 2014; Jiang et al., 2018), we here show that moisture was the relatively most important factor predicting bacterial wilt occurrence across broad geographical scale spanning six Chinese provinces. Our sampling area covered various soil types, tomato cultivars and climate conditions. While clear geographical variation between locations was observed, the significance of soil moisture on plant health status was significant within each field. As a result, this difference could not be explained by local climate or agricultural practises, such as use of certain tomato cultivars. In the future, it will be important to see if our findings can be extrapolated to other countries and agricultural areas experiencing recurrent $R$. solanacearum outbreaks.

In addition to identifying an important country-wide link with the soil moisture, we show that this association might not be 
an indirect consequence of $R$. solanacearum infection, which typically leads to increased soil moisture via reduced water uptake and transpiration in the infected plants (Jiang, 2016). Instead, by using controlled greenhouse experiment, we demonstrate that soil moisture alone can causally drive bacterial wilt disease outcomes in otherwise identical soil environmental conditions. Highest levels of disease incidence were observed at $60 \%$ and $70 \%$ maximum water holding capacity soil moisture treatments, and there are several potential reasons for this. First, it is possible that this moisture content level was optimal for the plant growth (Kramer, 1983) leading to more efficient root exudation (Larson and Funk, 2016) and improved growth and colonisation of the plant by the pathogen (van Elsas et al., 2000; Islam and Toyama, 2004). Moreover, non-optimal soil moisture levels have previously been shown to lead overexpression of plant resistance genes (Sinha et al., 2016; Jiang et al., 2018), which could have also affected the observed differences in disease occurrence, as reported before (Mondal et al., 2014). Alternatively, it is possible that certain moisture levels were directly beneficial to the pathogen, potentially allowing more efficient growth, movement and colonisation of the plant (Beattie, 2011; Aung et al., 2018; Velásquez et al., 2018). Finally, soil moisture is known to affect the availability of oxygen (Mainiero and Kazda, 2005) and nutrients (Cavagnaro, 2016), which could have affected the $R$. solanacearum growth (Dalsing et al., 2015) or the strength of microbiomemediated pathogen suppression (Chen et al., 2007; Brockett et al., 2012) in the rhizosphere. Further experiments are hence needed to test these explanations directly.

In addition to soil moisture, also some soil physiochemical properties, such as microbiome composition, $\mathrm{pH}$ and nitrogen availability, differed between healthy and diseased plants depending on the sampling sites. This is in line with previous findings showing a clear link between bacterial community composition and bacterial wilt disease outcomes (Wei et al., 2018, 2019), highlighting also the importance of microbial interactions for $R$. solanacearum infections (Wei et al., 2019; Wen et al., 2020; Lee et al., 2021). While differences in bacterial community richness and diversity of healthy and diseased plants were only significant in Nanjing, bacterial community composition was more consistently associated with plant health status indicative of its importance in predicting bacterial wilt disease occurrence (Wei et al., 2019). In the future, it would be interesting to test if the abundance and activity of certain $R$. solanacearum-suppressing bacteria, such Firmicutes and Actinobacteria (Lee et al., 2021), were positively or negatively affected by the soil moisture content. Furthermore, it has previously been shown that bacterial wilt disease is aggravated in acidic soils ( $\mathrm{Li}$ et al., 2017a, 2017b; Wang et al., 2017) and by high nitrogen availability (Y. Gu et al., 2020), while high C, N, P and K availabilities have been linked with healthy plant rhizosphere (Wang et al., 2017; Wei et al., 2018; Wu et al., 2020). However, we found that the physicochemical soil properties did not consistently differ between healthy and diseased plants by field sampling and machine learning algorithm. There might be a latent infection in healthy plants during field sampling, which could lead to an underestimate the difference of soil properties between non-infection healthy plant and diseased plants. In the future, it would be interesting to test if our algorithm can predict bacterial wilt disease occurrence using other unrelated data sets, and if its performance can be improved by taking latent infection into account, and including some other abiotic and biotic variables that vary temporally, such as temperature and humidity. Furthermore, it is likely that certain environmental factors will have interactive effects, which should be further explored experimentally.

\section{Conclusions}

We conclude that soil properties can be used as reliable predictors of bacterial wilt disease occurrence, with soil moisture being one of the most import single factors that consistently differed between healthy and diseased plants across all sampling locations. Moreover, while other soil properties played important roles, their effects were often sampling location-specific, indicative of their potential importance at the local scale. The causal role of soil moisture was directly validated in a greenhouse house experiments, which highlights the value of direct experimentation in separating causes from consequences in plant pathology studies. The obtained information will be helpful for developing predictive modeling to better understand the epidemiology of bacterial wilt disease outbreaks in spatially and temporally varying agricultural environments and should be validated in the future with unrelated data sets from other countries and agricultural areas. Finally, the importance of soil moisture suggests that relatively simple water management practises could potentially be effective way to control bacterial wilt disease occurrence.

\section{Acknowledgments}

We thank Dr. Alexandre Jousset and Dr. Zhipeng Liu for helpful discussions. This research was financially supported by the National Natural Science Foundation of China (41922053, 42090062, 31972504 and 42007038), and the Fundamental Research Funds for the Central Universities (KJQN202116KJQN202117, KYXK202009-KYXK202012), the Natural Science Foundation of Jiangsu Province (BK20190518, BK20180527 and BK20200533), the China Postdoctoral Science Foundation (2019M651848) and technically supported by the Bioinformatics Center of Nanjing Agricultural University. S.G. is funded by the NWO-Veni grant (016.Veni.181.078 to S.G.). V.F. is funded by the Royal Society (RSGIR1\180213 and CHLIR1\180031) and jointly by a grant from UKRI, Defra, and the Scottish Government, under the Strategic Priorities Fund Plant Bacterial Diseases programme (BB/T010606/1) at the University of York. 


\section{Conflict of interest}

The authors declare that there are no relevant conflicts of interest.

\section{References}

Aung, K., Jiang, Y., He, S.Y., 2018. The role of water in plant-microbe interactions. Plant Journal 93, 771-780.

Beattie, G.A., 2011. Water relations in the interaction of foliar bacterial pathogens with plants. Annual Review of Phytopathology 49, 533 555.

Berg, M., Koskella, B., 2018. Nutrient- and dose-dependent microbiome-mediated protection against a plant pathogen. Current Biology 28, 2487-2492.e3.

Breiman, L., and Cutler, A., for Fortran original, Liaw, A., and Wiener, M., for R. port 2018. randomForest: Breiman and Cutler's Random Forests for Classification and Regression.

Brockett, B.F.T., Prescott, C.E., Grayston, S.J., 2012. Soil moisture is the major factor influencing microbial community structure and enzyme activities across seven biogeoclimatic zones in western Canada. Soil Biology \& Biochemistry 44, 9-20.

Caporaso, J.G., Kuczynski, J., Stombaugh, J., Bittinger, K., Bushman, F.D., Costello, E.K., Fierer, N., Peña, A.G., Goodrich, J.K., Gordon, J.I., Huttley, G.A., Kelley, S.T., Knights, D., Koenig, J.E., Ley, R.E., Lozupone, C.A., McDonald, D., Muegge, B.D., Pirrung, M., Reeder, J., Sevinsky, J.R., Turnbaugh, P.J., Walters, W.A., Widmann, J., Yatsunenko, T., Zaneveld, J., Knight, R., 2010. QIIME allows analysis of high-throughput community sequencing data. Nature Methods 7, 335-336.

Cavagnaro, T.R., 2016. Soil moisture legacy effects: Impacts on soil nutrients, plants and mycorrhizal responsiveness. Soil Biology \& Biochemistry 95, 173-179.

Chairman, J.F.P., Gardner, W.R., Elliott, L.F., eds., 1981. Water potential relations in soil microbiology, SSSA Special Publications. John Wiley \& Sons, Ltd.

Chen, M.M., Zhu, Y.G., Su, Y.H., Chen, B.D., Fu, B.J., Marschner, P., 2007. Effects of soil moisture and plant interactions on the soil microbial community structure. European Journal of Soil Biology 43, 31-38.

Cheng, Y.T., Zhang, L., He, S.Y., 2019. Plant-microbe interactions facing environmental challenge. Cell Host \& Microbe 26, 183-192.

Cole, J.R., Wang, Q., Fish, J.A., Chai, B., McGarrell, D.M., Sun, Y., Brown, C.T., Porras-Alfaro, A., Kuske, C.R., Tiedje, J.M., 2014. Ribosomal Database Project: data and tools for high throughput rRNA analysis. Nucleic Acids Research 42, D633-D642.

Cuzick, J., 1985. A Wilcoxon-type test for trend. Statistics in Medicine 4, 87-90.

Dalsing, B.L., Truchon, A.N., Gonzalez-Orta, E.T., Milling, A.S., Allen, C., 2015. Ralstonia solanacearum uses inorganic nitrogen metabolism for virulence, ATP production, and detoxification in the oxygen-limited host xylem environment. mBio 6, e02471.

de Mendiburu, F., 2020. agricolae: Statistical Procedures for Agricultural Research. http://tarwi.lamolina.edu.pe/ fmendiburu

Dixon, P., 2003. VEGAN, a package of $R$ functions for community ecology. Journal of Vegetation Science 14, 927-930.
Edgar, R.C., 2010. Search and clustering orders of magnitude faster than BLAST. Bioinformatics (Oxford, England) 26, 2460-2461.

Fierer, N., Jackson, J.A., Vilgalys, R., Jackson, R.B., 2005. Assessment of soil microbial community structure by use of taxon-specific quantitative PCR assays. Applied and Environmental Microbiology $71,4117-4120$.

Genin, S., Denny, T.P., 2012. Pathogenomics of the Ralstonia solanacearum species complex. Annual Review of Phytopathology $50,67-89$.

Gu, S., Wei, Z., Shao, Z., Friman, V.P., Cao, K., Yang, T., Kramer, J., Wang, X., Li, M., Mei, X., Xu, Y., Shen, Q., Kümmerli, R., Jousset, A., 2020. Competition for iron drives phytopathogen control by natural rhizosphere microbiomes. Nature Microbiology 5, 1002 1010.

Gu, Y., Wang, X., Yang, T., Friman, V.P., Geisen, S., Wei, Z., Xu, Y., Jousset, A., Shen, Q., 2020. Chemical structure predicts the effect of plant-derived low-molecular weight compounds on soil microbiome structure and pathogen suppression. Functional Ecology 34, 2158-2169.

Hayward, A.C., 1991. Biology and epidemiology of bacterial wilt caused by Pseudomonas solanacearum. Annual Review of Phytopathology 29, 65-87.

Hothorn, T., Bretz, F., Westfall, P., 2008. Simultaneous inference in general parametric models. Biometrical Journal 50, 346-363

Huber, L., Gillespie, T.J., 1992. Modeling leaf wetness in relation to plant disease epidemiology. Annual Review of Phytopathology 30, 553-577.

Islam, T., Toyama, K., 2004. Effect of moisture conditions and preincubation at low temperature on bacterial wilt of tomato caused by Ralstonia solanacearum. Microbes and Environments 19, 244 247.

Janvier, C., Villeneuve, F., Alabouvette, C., Edel-Hermann, V., Mateille, T., Steinberg, C., 2007. Soil health through soil disease suppression: Which strategy from descriptors to indicators? Soil Biology \& Biochemistry 39, 1-23.

Jiang, G., 2016. Pathogenesis and modelling of infection dynamics in Ralstonia solanacearum (Thesis). Http://www.theses.fr. toulouse 3.

Jiang, G., Wei, Z., Xu, J., Chen, H., Zhang, Y., She, X., Macho, A.P., Ding, W., Liao, B., 2017. Bacterial wilt in China: History, current status, and future perspectives. Frontiers of Plant Science 8, 1549.

Jiang, Y., Huang, M., Zhang, M., Lan, J., Wang, W., Tao, X., Liu, Y., 2018. Transcriptome analysis provides novel insights into highsoil-moisture-elevated susceptibility to Ralstonia solanacearum infection in ginger (Zingiber officinale Roscoe cv. Southwest). Plant Physiology and Biochemistry 132, 547-556.

Kabacoff, R., ed., 2015. R in Action, 2nd Edition. Manning Publications Co., CTUnited States.

Kahm, M., Hasenbrink, G., Lichtenberg-Fraté, H., Ludwig, J., Kschischo, M., 2010. grofit: Fitting Biological Growth Curves with R. Journal of Statistical Software 33, 1-21.

Kearns, D.B., 2010. A field guide to bacterial swarming motility. Nature Reviews. Microbiology 8, 634-644.

Kramer, P.J., 1983. Water Relations of Plants. Elsevier Science, Oxford.

Kwak, M.J., Kong, H.G., Choi, K., Kwon, S.K., Song, J.Y., Lee, J., Lee, 
P.A., Choi, S.Y., Seo, M., Lee, H.J., Jung, E.J., Park, H., Roy, N., Kim, H., Lee, M.M., Rubin, E.M., Lee, S.W., Kim, J.F., 2018. Rhizosphere microbiome structure alters to enable wilt resistance in tomato. Nature Biotechnology 36, 1100-1109.

Larson, J.E., Funk, J.L., 2016. Seedling root responses to soil moisture and the identification of a belowground trait spectrum across three growth forms. New Phytologist 210, 827-838.

Lê, S., Josse, J., Husson, F., 2008. FactoMineR: an R package for multivariate analysis. Journal of Statistical Software 25, 1-18.

Lee, S.M., Kong, H.G., Song, G.C., Ryu, C.M., 2021. Disruption of Firmicutes and Actinobacteria abundance in tomato rhizosphere causes the incidence of bacterial wilt disease. ISME Journal 15 , 330-347.

Li, S., Liu, Y., Wang, J., Yang, L., Zhang, S., Xu, C., Ding, W., 2017a. Soil acidification aggravates the occurrence of bacterial wilt in south China. Frontiers in Microbiology 8, 703.

Li, S., Xu, C., Wang, J., Guo, B., Yang, L., Chen, J., Ding, W., 2017b. Cinnamic, myristic and fumaric acids in tobacco root exudates induce the infection of plants by Ralstonia solanacearum. Plant and Soil 412, 381-395.

Li, Y., Uddin, W., Kaminski, J.E., 2014. Effects of relative humidity on infection, colonization and conidiation of Magnaporthe orzyae on perennial ryegrass. Plant Pathology 63, 590-597.

Mainiero, R., Kazda, M., 2005. Effects of Carex rostrata on soil oxygen in relation to soil moisture. Plant and Soil 270, 311-320.

Mansfield, J., Genin, S., Magori, S., Citovsky, V., Sriariyanum, M. Ronald, P., Dow, M., Verdier, V., Beer, S.V., Machado, M.A., Toth, I., Salmond, G., Foster, G.D., 2012. Top 10 plant pathogenic bacteria in molecular plant pathology. Molecular Plant Pathology 13, 614-629.

Mondal, B., Bhattacharya, I., Khatua, D.C., 2014. Incidence of bacterial wilt disease in West Bengal, India. Academia Journal of Agricultural Research 2, 139-146.

Orr, R., Nelson, P.N., 2018. Impacts of soil abiotic attributes on Fusarium wilt, focusing on bananas. Applied Soil Ecology 132, 20 33.

Panchal, S., Chitrakar, R., Thompson, B.K., Obulareddy, N., Roy, D., Hambright, W.S., Melotto, M., 2016. Regulation of stomatal defense by air relative humidity. Plant Physiology 172, 2021-2032.

Pansu, M., Gautheyrou, J., eds., 2006. Handbook of Soil Analysis: Mineralogical, Organic and Inorganic Methods. Springer, Berlin, Heidelberg.

Patro, S.G.K., Sahu, K.K., 2015. Normalization: a preprocessing stage. ArXiv 1503.06462.

Peyraud, R., Cottret, L., Marmiesse, L., Genin, S., 2018. Control of primary metabolism by a virulence regulatory network promotes robustness in a plant pathogen. Nature Communications 9, 418.

Peyraud, R., Cottret, L., Marmiesse, L., Gouzy, J., Genin, S., 2016. A resource allocation trade-off between virulence and proliferation drives metabolic versatility in the plant pathogen Ralstonia solanacearum. PLoS Pathogens 12, e1005939.

Pimentel, C.S., Ayres, M.P., 2018. Latitudinal patterns in temperaturedependent growth rates of a forest pathogen. Journal of Thermal Biology 72, 39-43.

R Core Team, 2020. The R Stats Package.

Rahman, K.A., Othman, R., 2020. Influence of $\mathrm{pH}$ levels on disease development in oil palm seedling roots infected with Ganoderma boninensis. Rhizosphere 13, 100181.

Raza, W., Wang, J., Wu, Y., Ling, N., Wei, Z., Huang, Q., Shen, Q., 2016. Effects of volatile organic compounds produced by Bacillus amyloliquefaciens on the growth and virulence traits of tomato bacterial wilt pathogen Ralstonia solanacearum. Applied Microbiology and Biotechnology 100, 7639-7650.

Satou, M., Kubota, M., Nishi, K., 2006. Measurement of horizontal and vertical movement of Ralstonia solanacearum in soil. Journal of Phytopathology 154, 592-597.

Schandry, N., 2017. A practical guide to visualization and statistical analysis of $R$. solanacearum infection data using R. Frontiers of Plant Science 8, 623.

Schönfeld, J., Heuer, H., van Elsas, J.D., Smalla, K., 2003. Specific and sensitive detection of Ralstonia solanacearum in soil on the basis of PCR amplification of fliC fragments. Applied and Environmental Microbiology 69, 7248-7256.

Sinha, R., Gupta, A., Senthil-Kumar, M., 2016. Understanding the impact of drought on foliar and xylem invading bacterial pathogen stress in chickpea. Frontiers of Plant Science 7, 902.

Siregar, B.A., Giyanto, Hidayat, S.H., Siregar, I.Z., Tjahjono, B., 2020. Epidemiology of bacterial wilt disease on Eucalyptus pellita $\mathrm{F}$. Muell. in Indonesia. IOP Conference Series: Earth and Environmental Science 468, 012033.

Smilanick, J.L., Mansour, M.F., 2007. Influence of temperature and humidity on survival of Penicillium digitatum and Geotrichum citriaurantii. Plant Disease 91, 990-996.

Trivedi, P., Leach, J.E., Tringe, S.G., Sa, T., Singh, B.K., 2020. Plantmicrobiome interactions: from community assembly to plant health. Nature Reviews Microbiology 18, 607-621.

van Elsas, J.D., Kastelein, P., van Bekkum, P., van der Wolf, J.M., de Vries, P.M., van Overbeek, L.S., 2000. Survival of Ralstonia solanacearum Biovar 2, the causative agent of potato brown rot, in field and microcosm soils in temperate climates. Phytopathology 90, 1358-1366.

Velásquez, A.C., Castroverde, C.D.M., He, S.Y., 2018. Plant-pathogen warfare under changing climate conditions. Current Biology 28, R619-R634.

Wang, R., Zhang, H., Sun, L., Qi, G., Chen, S., Zhao, X., 2017. Microbial community composition is related to soil biological and chemical properties and bacterial wilt outbreak. Scientific Reports 7, 343.

Wei, Z., Friman, V.P., Pommier, T., Geisen, S., Jousset, A., Shen, Q., 2020. Rhizosphere immunity: targeting the underground for sustainable plant health management. Frontiers of Agricultural Science and Engineering 7, 317-328.

Wei, Z., Gu, Y., Friman, V.P., Kowalchuk, G.A., Xu, Y., Shen, Q., Jousset, A., 2019. Initial soil microbiome composition and functioning predetermine future plant health. Science Advances 5 , eaaw0759.

Wei, Z., Hu, J., Gu, Y., Yin, S., Xu, Y., Jousset, A., Shen, Q., Friman, V. P., 2018. Ralstonia solanacearum pathogen disrupts bacterial rhizosphere microbiome during an invasion. Soil Biology \& Biochemistry 118, 8-17.

Wei, Z., Huang, J., Yang, T., Jousset, A., Xu, Y., Shen, Q., Friman, V. P., 2017. Seasonal variation in the biocontrol efficiency of bacterial 
wilt is driven by temperature-mediated changes in bacterial competitive interactions. Journal of Applied Ecology 5, 14401448.

Wei, Z., Huang, J.F., Hu, J., Gu, Y.A., Yang, C.L., Mei, X.L., Shen, Q. R., Xu, Y.C., Friman, V.P., 2015a. Altering transplantation time to avoid periods of high temperature can efficiently reduce bacterial wilt disease incidence with tomato. PLoS One 10, e0139313.

Wei, Z., Yang, T., Friman, V.P., Xu, Y., Shen, Q., Jousset, A., 2015b. Trophic network architecture of root-associated bacterial communities determines pathogen invasion and plant health. Nature Communications 6, 8413.

Wei, Z., Yang, X., Yin, S., Shen, Q., Ran, W., Xu, Y., 2011. Efficacy of Bacillus-fortified organic fertiliser in controlling bacterial wilt of tomato in the field. Applied Soil Ecology 48, 152-159.

Wen, T., Zhao, M., Liu, T., Huang, Q., Yuan, J., Shen, Q., 2020. High abundance of Ralstonia solanacearum changed tomato rhizosphere microbiome and metabolome. BMC Plant Biology 20, 166.

Wickham, H., Chang, W., Henry, L., Pedersen, T.L., Takahashi, K., Wilke, C., Woo, K., Yutani, H., Dunnington, D., RStudio, 2020. ggplot2: Create Elegant Data Visualisations Using the Grammar of Graphics.

Wu, X., Li, H., Wang, Y., Zhang, X., 2020. Effects of bio-organic fertiliser fortified by Bacillus cereus QJ-1 on tobacco bacterial wilt control and soil quality improvement. Biocontrol Science and Technology 30, 351-369.

Xin, X.F., Nomura, K., Aung, K., Velásquez, A.C., Yao, J., Boutrot, F., Chang, J.H., Zipfel, C., He, S.Y., 2016. Bacteria establish an aqueous living space in plants crucial for virulence. Nature 539, 524-529. 